\title{
Substituição do farelo de soja por farelo de algodão de alta energia em dietas para vacas leiteiras em produção: consumo, digestibilidade dos nutrientes, balanço de nitrogênio e produção leiteira
}

\author{
Alisson Ferreira Alves ${ }^{1}$, Joanis Tilemahos Zervoudakis ${ }^{1}$, Luciana Keiko Hatamoto- \\ Zervoudakis $^{1}$, Luciano da Silva Cabral ${ }^{1}$, Fernando de Paula Leonel ${ }^{2}$, Nelcino Francisco de \\ Paula $^{3}$
}

\footnotetext{
${ }^{1}$ Programa de Pós-Graduação em Ciência Animal - Universidade Federal de Mato Grosso - Av. Fernando Correa da Costa.s/n. Cuiabá-MT, CEP: 78.060 .900

2 Universidade Federal de São João Del Rey.

3 Programa de Pós-Graduação em Zootecnia da Universidade Federal de Viçosa.
}

RESUMO - Avaliou-se o efeito da inclusão de níveis crescentes de farelo de algodão alta energia (0; 8,7; 17,4; 26,1 e $34,8 \%$ da matéria seca) em substituição ao farelo de soja no concentrado de vacas no terço final de lactação sobre o consumo e a digestibilidade dos nutrientes, a eficiência na utilização do nitrogênio e a produção de leite. Foram utilizadas cinco vacas mestiças 5/8 Holandês $\times 3 / 8$ Gir, em um delineamento quadrado latino $5 \times 5$, com cinco períodos de 18 dias (oito dias para adaptação e 10 dias para determinação do consumo e coleta de amostras). As dietas foram calculadas para terem teores proteicos semelhantes (14\% de proteína bruta), com $60 \%$ de silagem de milho e $40 \%$ de concentrado na MS. Não houve efeito da inclusão de farelo de algodão alta energia sobre os consumos de matéria seca, matéria orgânica, proteína bruta, carboidratos totais e nutrientes digestíveis totais. O consumo de extrato etéreo aumentou com os níveis de 26,1 e 34,8\% de farelo de algodão alta energia, enquanto o consumo de carboidratos não-fibrosos foi maior para os níveis de 0, 8,7 e 26,1\%. A digestibilidade dos nutrientes não diferiu entre os níveis de farelo de algodão alta energia. A substituição do farelo de soja pelo farelo de algodão não influenciou a eficiência de utilização e o balanço de nitrogênio, ou o teor de nitrogênio ureico no leite e de nitrogênio ureico no soro. A produção média de leite $(14,03 \mathrm{~kg} / \mathrm{dia})$ e a produção média de leite corrigida para 3,5\% de gordura $(14,68 \mathrm{~kg} / \mathrm{dia})$ não foram influenciadas pelos níveis de farelo de algodão alta energia na dieta nem houve diferença na eficiência alimentar. O farelo de algodão alta energia tem potencial para substituição do farelo de soja na dieta de vacas com capacidade de produção de $15 \mathrm{~kg} / \mathrm{dia}$.

Palavras-chave: alimentos alternativos, balanço proteico, concentrado, fibra em detergente neutro indigestível, valor nutritivo

\section{Replacing soybean meal with high energy cottonseed meal in diets for dairy yielding cows: intake, nutrient digestibility, nitrogen efficiency and milk yield}

ABSTRACT - The effect of replacing increasing levels of high-energy cottonseed meal (0, 8.7, 17.4, 26.1 and 34,8\% DM) with soybean meal in concentrate for cows in the final lactation third on intake, nutrient digestibility, nitrogen efficiency and milk yield was assessed. Five crossbred $5 / 8$ Holstein $\times 3 / 8$ Gir cows were allotted to a $5 \times 5$ Latin square design, with five 18-day periods (eight days for adaptation and 10 days to determine intake and collect samples). The diets were formulated to have similar protein contents (14\% CP), with $60 \%$ corn silage and $40 \%$ on the DM. There was no effect of including high energy cottonseed meal on the intakes of DM, organic matter (OM), crude protein (CP), total carbohydrates (TCHO) and total digestible nutrients). The EE intake increased with levels of 26.1 and $34.8 \%$ of high energy cottonseed meal inclusion, while the non-fibrous carbohydrate (NFC) intake was higher for levels of 0, 8.7 and 26.1\%. The digestibility coefficients of the nutrients did not differ among the high energy cottonseed meal levels experimental diets. Replacing soybean hulls levels with high energy cottonseed meal did not influence the nitrogen use efficiency or balance, or the milk urea nitrogen content (MUN) and blood urea nitrogen (BUN). Average milk yield (14.03 kg/day) and milk yield corrected for $3.5 \%$ fat milk fat (14.68 $\mathrm{kg} /$ day) were not influenced by the different levels of high-energy cottonseed meal in the diet and there was no difference for feed efficiency. High-energy cottonseed meal presents potential for replacing soybean meal in the diet of cows with $15 \mathrm{~kg} /$ day production capacity.

Key Words: alternative feed, concentrate, indigestible neutral detergent fiber, nutritive value, protein balance

Recebido em 8/7/2008 e aprovado em 16/3/2009.

Correspondências devem ser enviadas para: joanis@ufmt.br 


\section{Introdução}

O consumo de matéria seca é primordial para uma resposta produtiva adequada, pois é o principal determinante da quantidade de nutrientes, especialmente energia e proteína, que estarão disponíveis para atendimento das exigências de mantença e produção. A proteína é o segundo nutriente limitante em dietas para animais ruminantes, no entanto, as fontes proteicas são os ingredientes mais onerosos na formulação de dietas para vacas lactantes, devido ao alto requerimento e elevado custo. Assim, o uso de fontes proteicas alternativas pode otimizar os resultados, seja pela redução nos custos de produção seja pela melhor adequação dos nutrientes disponíveis às necessidades metabólicas do animal (PINA, 2005).

Nesse contexto, o suprimento de proteína em termos quantitativos e qualitativos merece destaque pela elevada exigência desse nutriente e pela variabilidade da resposta às diferentes fontes de compostos nitrogenados disponíveis (NRC, 2001).

O farelo de algodão tem sido utilizado com o objetivo de reduzir o uso de farelo de soja visando à obtenção de condições econômicas mais vantajosas e, embora apresente menores teores de energia e proteína, é caracterizado pelo seu maior teor de proteína não-degradável no rúmen (NRC, 2001). Nesse sentido, a avaliação do farelo de algodão de alta energia, obtido por extrusão do caroço de algodão semideslintado durante o processo de extração do óleo ganha importância, pois são escassos os estudos sobre sua utilização em dietas para vacas em lactação (Bunge Alimentos, 2007).

A importância da proteína na formulação de dietas não se limita à sua fonte alimentar, uma vez que a economia da produção animal é altamente dependente da eficiência de utilização do nitrogênio dietético para produção de proteína do leite, que é de apenas 25 a 30\%. Para que seja possível obter a produtividade animal desejada, a melhoria na eficiência de uso da proteína bruta (PB) dietética é fundamental, tornando necessária a avaliação de fontes proteicas que atendam às necessidades de nitrogênio $(\mathrm{N})$ dos microrganismos ruminais (Bequette et al., 1998).

O monitoramento do consumo de PB dietética por meio da análise dos teores de nitrogênio uréico no sangue (NUS) e nitrogênio ureico no leite (NUL) parece ser estratégia efetiva para reduzir as perdas de nitrogênio (Broderick \& Clayton, 1997). O aumento na eficiência de uso do nitrogênio reduz os gastos com alimento por unidade de ganho de peso ou de proteína secretada no leite e diminui a eliminação de compostos nitrogenados no ambiente (NRC, 2001). Dessa forma, Rennó et al. (2008) destacaram que a eficiência bioeconômica é influenciada por outros fatores além do nível de produção de leite, como as quantidades e os custos dos nutrientes utilizados, bem como a receita com o produto obtido dentro de um cenário específico de produção.

Dessa forma, objetivou-se avaliar o efeito de níveis crescentes de farelo de algodão de alta energia em substituição ao farelo de soja em dietas para vacas leiteiras sobre o consumo, a digestibilidade aparente dos nutrientes, a eficiência na utilização do nitrogênio e a produção de leite.

\section{Material e Métodos}

O experimento foi conduzido nas instalações do Setor de Bovinocultura Leiteira da Fazenda Experimental da Universidade Federal de Mato Grosso (UFMT), localizado no município de Santo Antônio do Leverger/MT, no período de 10 de abril a 22 de julho de 2007. O clima da região é do tipo Cwa de Köepen, tropical, sazonal, com duas estações bem definidas, verão chuvoso (outubro a março) e inverno seco (abril a setembro). Durante o período experimental, a temperatura média foi de $23^{\circ} \mathrm{C}$, com máxima de $36,3^{\circ} \mathrm{C}$ e mínima de $10,3^{\circ} \mathrm{C}$, e umidade relativa média de $74,9 \%$, segundo dados coletados na Estação Meteorológica da Fazenda Experimental da Universidade Federal de Mato Grosso.

Os animais foram mantidos em galpão coberto, provido de cochos individuais, com piso de concreto e área de descanso coletiva com livre acesso aos bebedouros e sombra.

Foram utilizadas cinco vacas da raça Girolando mestiças Holandês-Gir (5/8 H × 3/8G, Holandês e Gir Leiteiro, respectivamente) com peso vivo médio inicial de 524,7 kg e com período médio de lactação de 304 dias $( \pm 42)$ e produção média de leite de $15 \mathrm{~kg} / \mathrm{dia}$, que correspondem a valores obtidos durante a realização do experimento. O delineamento experimental utilizado foi o quadrado latino $5 \times 5$ ( 5 animais $\times 5$ períodos experimentais), com distribuição aleatória dos tratamentos para cada animal, de forma a garantir que não houvesse repetição da combinação de dietas.

O experimento foi delineado para avaliar cinco níveis de inclusão de farelo de algodão de alta energia ( $0 ; 8,7$; 17,$4 ; 26,1$ e 34,8\% da matéria seca do concentrado) em substituição ao farelo de soja em dietas para vacas em lactação, com relação volumoso:concentrado de 60:40, formuladas para terem teores proteicos semelhantes (14\% de PB na MS). Os ingredientes utilizados foram: silagem de milho, milho moído fino, farelo de soja, farelo de algodão de alta energia, uréia:sulfato de amônio e suplemento mineral (Tabela 1). 
Tabela 1 - Composição em ingredientes utilizados nas dietas experimentais

\begin{tabular}{|c|c|c|c|c|c|}
\hline \multirow[t]{2}{*}{ Ingrediente } & \multicolumn{5}{|c|}{ Nível de farelo de algodão alta energia (\% MS) } \\
\hline & 0 & 8,7 & 17,4 & 26,1 & 34,8 \\
\hline Silagem de milho & 60,00 & 60,00 & 60,00 & 60,00 & 60,00 \\
\hline Farelo de soja & 13,70 & 11,65 & 9,59 & 7,54 & 5,48 \\
\hline Farelo de algodão ${ }^{1}$ & 0,00 & 3,48 & 6,96 & 10,44 & 13,92 \\
\hline Milho moído & 24,9 & 0 & 23,44 & 21,97 & 20,50 \\
\hline \multicolumn{6}{|l|}{19,02} \\
\hline Ureia:sulfato de amônio (9:1) & 0,60 & 0,63 & 0,68 & 0,73 & 0,78 \\
\hline Mistura mineral ${ }^{2}$ & 0,80 & 0,80 & 0,80 & 0,80 & 0,80 \\
\hline
\end{tabular}

${ }^{1}$ Farelo de algodão de alta energia (Bunge Alimentos, 2007).

2 Níveis de garantia: cálcio - 18 g; fósforo - 81 g; sódio - 104 g; magnésio - 15,3 g; enxofre - 9,6 g; iodo - 49 mg; ferro - 517 mg; selênio - 27 mg; cobalto $100 \mathrm{mg}$; manganês - $1.000 \mathrm{mg}$; flúor - $810 \mathrm{mg}$; cobre - $1.600 \mathrm{mg}$; e zinco - $6.000 \mathrm{mg}$.

O arraçoamento foi realizado às 8 h e às 16 h, logo após as ordenhas, misturando-se a ração concentrada e a silagem em cochos individuais. As sobras de alimento foram pesadas e descartadas (exceto no período de coleta de amostras) depois de cada arraçoamento para ajuste na quantidade a ser oferecida ao mínimo de $10 \%$ de sobras, com base na matéria natural.

Os animais foram submetidos a um período préexperimental de 30 dias, para adaptação ao manejo, no qual foi utilizada uma dieta intermediária. O experimento teve duração de 90 dias, divididos em cinco períodos de 18 dias, os oito primeiros para adaptação dos animais às dietas, conforme proposto por Oliveira et al. (2001), e os dez dias restantes para coleta de dados. Os animais foram pesados no início e no final de cada período experimental, em dois dias consecutivos, antes da ordenha da manhã, para ajuste na oferta de alimento à proporção de 2,8\% de MS/kg de peso vivo (PV).

As amostras de concentrado foram coletadas no início de cada período de coleta de dados, assim como as amostras da silagem de milho e das sobras, que foram coletadas nos últimos quatro dias de cada período experimental. Imediatamente após a coleta, as amostras foram devidamente acondicionadas em sacos plásticos identificados e armazenadas em freezer a $-18^{\circ} \mathrm{C}$, para posteriores análises laboratoriais.

Para análise químico-bromatológica, as amostras de concentrado, silagem de milho e das sobras foram compostas por animal e por período e posteriormente submetidas à secagem em estufa de ventilação forçada a $55^{\circ} \mathrm{C}$ durante 72 horas, moídas em moinho com peneira e analisadas para determinação dos teores de matéria seca (MS), matéria orgânica (MO), matéria mineral (MM), proteína bruta $(\mathrm{PB})$ e extrato etéreo (EE), segundo Silva \& Queiroz (2002), e de fibra em detergente neutro (FDN) e fibra em detergente ácido (FDA), de acordo com Van Soest et al. (1991) (Tabelas 2 e 3).

Os teores de carboidratos totais dos alimentos (CT) e os teores de carboidratos não-fibrosos (CNF) foram calculados segundo Sniffen et al. (1992):

$\mathrm{CT}=100-(\% \mathrm{~PB}+\% \mathrm{EE}+\%$ Cinzas $) ; \mathrm{e} C N F=\mathrm{CT}-\mathrm{FDN}$.

Os teores de nutrientes digestíveis totais (NDT) nas dietas foram estimados segundo o NRC (2001), de modo que:

NDT $(\%)=$ PBD + FDND + CNFD + 2,25EED - 7, em que:

PBD = proteína bruta digestível; FDND = fibra em detergente neutro digestível;

CNFD = carboidratos não-fibrosos digestíveis; EED = extrato etéreo digestível.

Tabela 2 - Composição nutricional dos concentrados e da silagem de milho

\begin{tabular}{|c|c|c|c|c|c|c|}
\hline \multirow[t]{2}{*}{ Item } & \multicolumn{5}{|c|}{ Nível de farelo de algodão alta energia (\%) } & \multirow[t]{2}{*}{ Silagem de milho } \\
\hline & 0 & 8,7 & 17,4 & 26,1 & 34,8 & \\
\hline Matéria seca (\% MN) & 82,69 & 82,72 & 82,11 & 82,94 & 83,89 & 34,34 \\
\hline Matéria orgânica (\% MS) & 95,12 & 94,16 & 94,42 & 94,23 & 94,27 & 95,36 \\
\hline Matéria mineral (\% MS) & 4,88 & 5,84 & 5,58 & 5,77 & 5,73 & 4,64 \\
\hline Proteína bruta (\% MS) & 26,55 & 26,36 & 26,51 & 26,61 & 25,49 & 6,71 \\
\hline Extrato etéreo (\% MS) & 2,30 & 3,20 & 3,24 & 4,01 & 4,87 & 2,29 \\
\hline Fibra em detergente neutro (\% MS) & 14,48 & 16,12 & 18,66 & 20,23 & 21,33 & 54,48 \\
\hline Fibra em detergente ácido & 3,97 & 6,03 & 8,39 & 8,40 & 9,14 & 27,97 \\
\hline Carboidratos não-fibrosos (\% MS) & 51,79 & 48,48 & 46,02 & 43,38 & 42,58 & 32,31 \\
\hline Carboidratos totais (\% MS) & 66,27 & 64,60 & 64,67 & 63,61 & 63,91 & 86,79 \\
\hline
\end{tabular}

MN - matéria natural; MS - matéria seca. 
Tabela 3 - Composição nutricional nas dietas experimentais

\begin{tabular}{|c|c|c|c|c|c|}
\hline \multirow[t]{2}{*}{ Ingrediente } & \multicolumn{5}{|c|}{ Nível de farelo de algodão alta energia (\% MS) } \\
\hline & 0 & 8,7 & 17,4 & 26,1 & 34,8 \\
\hline Matéria seca $(\% \mathrm{MN})$ & 53,68 & 53,69 & 53,45 & 53,78 & 54,16 \\
\hline Matéria orgânica (\%MS) & 95,26 & 94,88 & 94,98 & 94,91 & 94,92 \\
\hline Matéria mineral (\%MS) & 4,74 & 5,12 & 5,02 & 5,09 & 5,08 \\
\hline Proteína bruta (\%MS) & 14,65 & 14,57 & 14,63 & 14,67 & 14,22 \\
\hline Extrato etéreo (\%MS) & 2,30 & 2,66 & 2,67 & 2,98 & 3,33 \\
\hline Fibra em detergente neutro (\%MS) & 38,48 & 39,14 & 40,15 & 40,78 & 41,22 \\
\hline Fibra em detergente ácido & 18,37 & 19,20 & 20,14 & 20,14 & 20,44 \\
\hline Carboidratos não-fibrosos (\%MS) & 39,84 & 38,51 & 37,53 & 36,47 & 36,15 \\
\hline Carboidratos totais (\%MS) & 78,32 & 77,65 & 77,68 & 77,26 & 77,38 \\
\hline FDNi (\%MS) & 15,24 & 14,86 & 15,09 & 15,12 & 14,99 \\
\hline
\end{tabular}

MN = matéria natural; MS - matéria seca; FDNi = fibra em detergente neutro indigestível.

Para determinação da digestibilidade aparente dos nutrientes, foi realizada diariamente a coleta de fezes dos animais nos quatro últimos dias de cada período experimental, diretamente na ampola retal, perfazendo uma amostra composta por animal em cada período. A excreção fecal utilizada na determinação da digestibilidade aparente dos alimentos foi estimada por meio das concentrações de fibra em detergente neutro indigestível (FDNi), obtidas após a incubação ruminal in situ dos alimentos, das sobras e das fezes por 144 horas em dois bovinos mestiços pesando em média $450 \mathrm{~kg}$ e fistulados no rúmen, conforme metodologia descrita por Cochran et al. (1986).

As vacas foram ordenhadas mecanicamente duas vezes ao dia, fazendo-se o registro da produção de leite por meio de dispositivo medidor de leite acoplado à ordenhadeira. Amostras de leite foram coletadas no 16으 e $17^{0}$ dia de cada período nas ordenhas da manhã e da tarde, que posteriormente foram compostas proporcionalmente por dia, acondicionadas em frascos plásticos com conservante (Bronopol ${ }^{\circledR}$ ) e analisadas para nitrogênio ureico pelo analisador ChemSpec 150, pelo método enzimático e espectrofotométrico, no Laboratório da Clínica do Leite do Departamento de Zootecnia da Escola Superior de Agricultura “Luiz de Queiroz”.

A produção de leite corrigida para 3,5\% de gordura (LCG 3,5) foi estimada segundo Sklan et al. (1992) pela seguinte equação:

LCG 3,5 = $(0,432+0,1625 \times \%$ gordura do leite $) \times$ produção de leite (kg/dia)

A eficiência alimentar foi calculada para cada vaca, dividindo-se a produção média de LCG 3,5 pela ingestão média de MS em cada período experimental (Pina et al., 2006b).

As amostras de sangue foram coletas no 18ํㅡ dia de cada período experimental, quatro horas após a alimentação matinal. As amostras foram centrifugadas em $3000 \mathrm{x}$ g por
20 minutos, armazenadas em tubos tipo eppendorf a $-10^{\circ} \mathrm{C}$ e posteriormente analisadas para determinação da composição em ureia pelo kit Analisa (Analisa Indústria e Comércio Ltda.), método colorimétrico. O teor de ureia foi convertido para nitrogênio ureico considerando 46,6\% de nitrogênio na ureia.

Amostras spot de urina foram obtidas no $18^{\circ}$ dia de cada período experimental, aproximadamente quatro horas após a alimentação, durante micção espontânea. Alíquotas de $10 \mathrm{~mL}$ dessa amostra foram filtradas e diluídas imediatamente em $40 \mathrm{~mL}$ de $_{2} \mathrm{SO}_{4}$ a $0,036 \mathrm{~N}$ para posteriores análises de ureia e creatinina, conforme proposto por Oliveira et al. (2001). Posteriormente, foram transferidas para tubos tipo eppendorf e analisadas quanto aos teores de ureia, pelo mesmo método que as amostras de sangue, e creatinina, pelo método de ponto final, com utilização de picrato e acidificante de kits comerciais.

A excreção urinária diária de creatinina foi estimada a partir da proposição de 23,41 mg/kg, obtida pelo produto do volume excretado e da concentração de creatinina urinária da coleta total. Dessa forma, o volume urinário total diário foi estimado dividindo-se as excreções urinárias diárias de creatinina pela concentração de creatinina na urina (Oliveira et al., 2001).

O cálculo da eficiência de utilização de nitrogênio foi realizado dividindo-se o $\mathrm{N}$-total médio do leite pela ingestão média de nitrogênio da dieta (Broderick, 2003).

Os dados de consumo e digestibilidade dos nutrientes, da utilização do nitrogênio e produção de leite foram submetidos à análise de variância pelo seguinte modelo estatístico e as médias, comparadas pelo teste Dunett. Em seguida foi realizada a análise de regressão dos dados obtidos com os níveis de substituição maiores que zero $(8,7 ; 17,4 ; 26,1$ e 34,8\%). Em todas as análises, foi utilizado o nível de significância de 5\%, no programa estatístico SAS (SAS, 2001). 


\section{Resultados e Discussão}

Neste ensaio, não foram determinados efeitos lineares, quadráticos e cúbicos $(\mathrm{P}>0,05)$ do tratamento sobre as variáveis avaliadas. A inclusão do farelo de algodão de alta energia não interferiu $(\mathrm{P}>0,05)$ nos consumos de MS, MO, FDN e NDT (Tabela 4). Pina et al. (2006b), que avaliaram dietas contendo 15,5\% de PB na MS, com $60 \%$ de silagem de milho e inclusão de $55,47 \%$ de farelo de algodão no concentrado, fornecidas a vacas da raça Holandesa com produção média de 25 kg de leite/ dia, também não verificaram diferenças entre os níveis de farelo de algodão de alta energia no concentrado sobre o consumo de MS e MO.

Os consumos de matéria seca obtidos neste estudo foram numericamente inferiores aos relatados por Pina et al. (2006b), de 18,57 a 19,56 kg/dia, e correspondem a valores de 3,22 a 3,40\% do PV. Em todos os níveis de farelo de algodão neste experimento (13,69 a 14,83 kg/dia), o consumo de MS foi próximo ao descrito pelo NRC (2001), que preconiza consumo de MS de 14,1 kg/dia para vacas com média de $525 \mathrm{~kg}$ de PV, produção de leite corrigida para 3,5\% de gordura (LCG 3,5) de $15 \mathrm{~kg}$ de leite e percentual de proteína no leite de $3,2 \%$. Isso porqueas vacas tendem a consumir alimento para atender às necessidades de energia e o consumo é direcionado pela produção de leite (NRC, 2001). Chizzotti et al. (2007) obtiveram resultado semelhante aos observados neste estudo ao avaliarem vacas Holandesas de acordo com o nível de produção de leite, com os animais caracterizados como de média produção consumindo 15,61 kg de MS/dia para produção de leite de 18,54 kg/dia.
Também não foi observado efeito $(\mathrm{P}>0,05)$ da inclusão de níveis crescentes de farelo de algodão de alta energia sobre os consumos de PB e carboidratos totais (Tabela 4), uma vez que o consumo de MS foi semelhante entre os tratamentos e a composição das dietas não apresentaram variação significativa desses nutrientes. Apesar do aumento da quantidade de FDN na composição das dietas com a inclusão do farelo de algodão, isso não foi suficiente para promover alteração significativa no consumo de FDN. A análise bromatológica do farelo de algodão alta energia apresentou a seguinte composição percentual: $\mathrm{PB}=25,5 ; \mathrm{FDNcp}=36,11 ; \mathrm{FDA}=23,69 ; \mathrm{EE}=9,00 ; \mathrm{MM}=$ 6,$8 ; \mathrm{NIDN} \% \mathrm{NT}=5,40 ; \mathrm{NIDA} \% \mathrm{NT}=4,36$; $\mathrm{CNF}=22,85$; LIGNINA $=6,022 \mathrm{eNDT}=74,53$.

O maior consumo de $\mathrm{EE}(\mathrm{P}<0,05)$ foi observado quando fornecidas as dietas com 26,1 e 34,8\% de farelo de algodão de alta energia (Tabela 4), fato relacionado à maior quantidade de EE nessas dietas (Tabela 3). Por outro lado, o consumo de CNF foi estatisticamente mais baixo $(\mathrm{p}<0,05)$ quando fornecidas as dietas com $17,4 \%$ e $34,8 \%$ de farelo de algodão (5,28 e 5,38 kg/dia, respectivamente), enquanto a dieta controle promoveu o maior valor de consumo desse nutriente $(6,24 \mathrm{~kg} / \mathrm{dia})$, uma vez que é utilizado no cálculo para estimar a quantidade de CNF (Tabela 3). Além disso, com a inclusão do farelo de algodão de alta energia, reduziuse a quantidade de milho nas dietas, que apresenta maior teor de CNF em sua composição.

De acordo com Mertens (1987), a ingestão de MS aumenta quando a ingestão de FDN é de $12 \pm 1,0 \mathrm{~g} / \mathrm{kg}$ de PV e, acima deste valor, a repleção ruminal limitaria o consumo, o que não se aplicaria às dietas avaliadas, pois o consumo

Tabela 4 - Consumos diários de nutrientes em vacas leiteiras alimentadas com dietas contendo farelo de algodão de alta energia em substituição ao farelo de soja

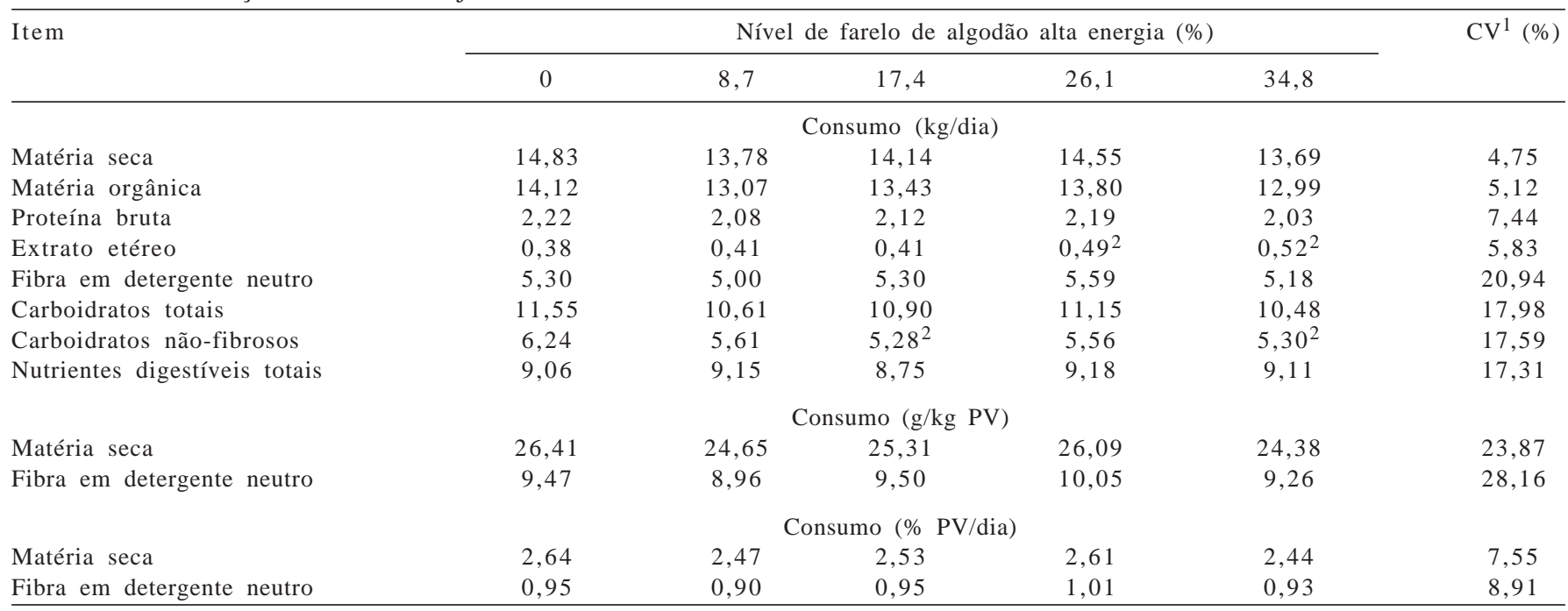

${ }^{1} \mathrm{CV}=$ coeficiente de variação.

2 Indica que a média do tratamento difere da média do tratamento controle $(\mathrm{P}>0,05)$ pelo teste Dunett. 
de FDN observado variou de 8,96 a 10,05 g/kg de PV. Dessa forma, os consumos das dietas avaliadas seriam controlados por fatores fisiológicos, ou seja, pela demanda energética dos animais ou por modulação psicogênica (Mertens, 1987). Resultado semelhante (10,36 g FDN/kg PV) foi obtido por Oliveira (2007), que trabalhou com animais de mesmo padrão racial e dieta semelhante $(60 \%$ de silagem de milho e $40 \%$ de concentrado, com 13,13\% de PB).

A utilização de ureia:sulfato de amônio para balanceamento das dietas em 0,60; 0,63; 0,68; 0,73 e 0,78\% da MS, respectivamente, para os níveis 0, 8,7; 17,4; 26,1 e $35,8 \%$ de farelo de algodão, não prejudicou o consumo de MS, o que está de acordo com Santos et al. (1998) e Pina et al. (2006b), que não observaram diferenças entre os níveis de ureia nas dietas. Oliveira et al. (2001) e Silva et al. (2001), no entanto, observaram influência negativa da inclusão de ureia:sulfato de amônio no consumo de MS, representada por decréscimos lineares com o aumento do nível de ureia, de 0 a 2,1\% da MS total.

Os teores de CNF nas dietas, que variaram de 36,15 a 39,84\% da MS, foram superiores ao valor citado por Valadares Filho et al. (2000) de 34\% de CNF em dietas a base de silagem de alfafa, que favoreceria o rendimento máximo de gordura no leite, e semelhantes aos valores citados como relacionados ao máximo consumo de matéria seca (37\%) e à máxima produção= de LCG 3,5 (38\%), o que aparentemente indica o controle do consumo por fatores fisiológicos. Por outro lado, Detmann et al. (2003) afirmaram que aparentemente existe uma fase de transição entre os controles físicos e fisiológicos sobre o consumo que se encontra entre os níveis dietéticos de FDN de 39 a 44\% na MS para bovinos confinados alimentados com forrageiras tropicais, o que se aplicaria aos valores obtidos de 38,48\% a 41,22\%de FDN na MS das dietas avaliadas neste estudo.
Não foi observado efeito $(\mathrm{P}>0,05)$ dos níveis de farelo de algodão de alta energia sobre as digestibilidades da MS, MO, PB, FDN, CNF e carboidratos totais (Tabela 5). As médias dos valores de digestibilidade da MS e MO foram semelhantes às obtidas por Pina et al. (2006b) para as dietas com farelo de algodão com 38\% PB (61,81 e 63,36\%) e $28 \%$ PB (59,85 e 61,04\%), assim como os valores médios de NDT das dietas avaliadas neste estudo.

A digestibilidade do EE foi maior quando as vacas foram alimentadas com as dietas com 8,7; 17,4 e 34,8\% de farelo de algodão alta energia no concentrado (Tabela 5), fato que provavelmente está relacionado ao maior consumo de EE ocasionado pela maior inclusão de farelo de algodão de alta energia (Tabela 4).

Não foi verificado efeito $(\mathrm{P}>0,05)$ da substituição do farelo de soja por farelo de algodão nos níveis avaliados sobre a eficiência de utilização e o balanço de nitrogênio, nem sobre os teores de NUL e NUS (Tabela 6). Não foi possível determinar os efeitos lineares, quadráticos e cúbicos dos níveis de farelo de algodão sobre o consumo diário de nitrogênio, a eficiência de utilização do nitrogênio, as concentrações de NUL e NUS e o balanço de nitrogênio.

Os limites de conversão do nitrogênio alimentar em nitrogênio no leite não são claramente definidos. $\mathrm{Na}$ tentativa de estabelecer essa eficiência de conversão, foram avaliados por Chase (2003), citado por Pina et al. (2006b), 334 tratamentos, provenientes de 62 pesquisas, e determinado valor médio de 0,270 , além da identificação de diversos fatores que afetam a eficiência de utilização de nitrogênio. Entre esses fatores, destacam-se o cruzamento, a ordem de lactação, o estágio de lactação, o conteúdo de proteína do leite, a fonte de carboidratos e a quantidade e qualidade da proteína dietética.

Os valores observados neste estudo foram inferiores aos relatados por Jonker et al. (1998), que observaram valor

Tabela 5 - Digestibilidade aparente total de nutrientes das dietas experimentais

\begin{tabular}{|c|c|c|c|c|c|c|c|}
\hline \multirow[t]{3}{*}{ Item $^{1}$} & \multicolumn{5}{|c|}{ Digestibilidade (\%) } & \multirow[t]{3}{*}{ Média } & \multirow[t]{3}{*}{ CV $(\%)^{1}$} \\
\hline & \multicolumn{5}{|c|}{ Farelo de algodão alta energia no concentrado (\%) } & & \\
\hline & 0 & 8,7 & 17,4 & 26,1 & 34,8 & & \\
\hline Matéria seca & 58,50 & 65,39 & 61,95 & 60,85 & 64,17 & 62,17 & 9,87 \\
\hline Matéria orgânica & 61,45 & 67,73 & 64,42 & 63,16 & 66,28 & 64,61 & 8,67 \\
\hline Proteína bruta & 64,38 & 63,39 & 61,62 & 61,64 & 64,67 & 63,14 & 15,71 \\
\hline Extrato etéreo & 80,09 & 86,30 & 80,27 & $87,30^{2}$ & $88,10^{2}$ & 84,41 & 9,00 \\
\hline Fibra em detergente neutro & 36,42 & 46,64 & 43,29 & 40,53 & 39,43 & 41,26 & 29,64 \\
\hline Carboidratos totais & 60,81 & 67,27 & 64,66 & 61,90 & 64,99 & 63,92 & 8,20 \\
\hline \multirow[t]{2}{*}{ Carboidratos não-fibrosos } & 81,34 & 85,63 & 83,87 & 82,38 & 85,26 & 83,70 & 31,88 \\
\hline & \multicolumn{5}{|c|}{ Valor energético das dietas (\% MS) } & & \\
\hline Nutrientes digestíveis totais & 61,55 & 67,03 & 61,85 & 63,31 & 67,17 & 64,18 & 59,52 \\
\hline
\end{tabular}

${ }^{1} \mathrm{CV}=$ coeficiente de variação.

2 Indica que a média do tratamento difere da média do tratamento controle $(\mathrm{P}>0,05)$ pelo teste Dunett. 
médio de 0,283 $\pm 0,037(\mathrm{n}=70)$ para eficiência de utilização do nitrogênio ao analisarem dados referentes a 40 vacas e 10 dietas para desenvolvimento de um modelo de predição da eficiência de utilização de nitrogênio. Pina et al. (2006b) observaram que a eficiência de utilização de nitrogênio também foi menor para as dietas à base de farelo de algodão (0,217 para farelo de algodão 38\% e 0,224 para farelo de algodão 28\%) e atribuiu esse resultado ao menor valor biológico da proteína do farelo de algodão em relação à proteína do farelo de soja.

A concentração elevada de ureia no sangue, que representa o produto final do metabolismo do nitrogênio, também é indicativa de ineficiência no aproveitamento da PB dietética. Além disso, como a concentração de ureia no sangue rapidamente se equilibra com a concentração no leite, há alta correlação entre essas duas variáveis (Broderick \& Clayton, 1997).

Neste estudo, apesar da diferença numérica, não foi possível demonstrar efeito estatístico $(\mathrm{P}>0,05)$ da inclusão de farelo de algodão de alta energia no concentrado sobre os teores de NUL e NUS (Tabela 6). Pina et al. (2006a) também não encontraram diferença entre as dietas contendo farelo de algodão ou ureia em substituição ao farelo de soja nos valores de NUL, entretanto os valores médios foram inferiores aos encontrados neste trabalho (farelo de soja $=15,26$, farelo de algodão $38 \%=12,45$, farelo de algodão $28 \%=12,65$ e farelo de soja e ureia $=15,13 \mathrm{mg} / \mathrm{dL}$ ).
Ipharraguerre \& Clark (2005), avaliando dietas com níveis crescentes de PB (14,8; 16,8 e 18,7\% na MS) para vacas de alta produção (40 kg de leite/dia), observaram valores de NUL de 8,20 a $14,97 \mathrm{mg} / \mathrm{dL}$, em resposta ao aumento na concentração da PB da dieta, corroborando os resultados obtidos por Colmenero \& Broderick (2006) e por Cordeiro et al. (2007), que aumentando o nível de PB na dieta (\%MS) para vacas produzindo em média $12 \mathrm{~kg}$ de leite/dia. Cordeiro et al. (2007) ao observarem aumento linear na concentração de NUL, que variou de 8,56 mg/dL (11,5 \% PB na MS) a 13,33 mg/dL (16,0\% PB na MS), o que demonstra forte correlação ( $\left.\mathrm{Y}=-3,5071+1,0591 \mathrm{X} ; \mathrm{r}^{2}=0,99\right)$ entre o teor de proteína bruta da dieta e a concentração de NUL, entretanto neste trabalho não foi possível observar este comportamento. Embora os resultados estejam dentro do intervalo proposto por Jonker et al. (1998), de 10 a $16 \mathrm{mg} / \mathrm{dL}$, estão acima da média encontrada por Jonker et al. (2002), que foi de $12,4 \mathrm{mg} / \mathrm{dL}$, obtida em 1.138 propriedades. Dessa forma, os valores nesse estudo deveriam ter sido menores, tendo em vista o teor de PB das dietas.

Não foi observada diferença na PL e LCG 3,5 atribuída aos níveis de farelo de algodão ( $\mathrm{P}>0,05)$, o que pode ser explicado pelo consumo de matéria seca, que não diferiu entre as dietas (Tabela 7). Esses resultados estão de acordo com os encontrados por Pina et al. (2006b), que avaliaram dietas contendo $15,5 \%$ de PB na MS, com $55,47 \%$ de farelo de algodão no concentrado, para vacas

Tabela 6 - Consumo diário de nitrogênio, da eficiência de utilização do nitrogênio, concentração de nitrogênio ureico do leite (NUL) e nitrogênio ureico no sangue (NUS) e balanço de nitrogênio das dietas experimentais

\begin{tabular}{|c|c|c|c|c|c|c|}
\hline \multirow[t]{2}{*}{ Item } & \multicolumn{5}{|c|}{ Nível de farelo de algodão alta energia no concetrado (\%) } & \multirow[t]{2}{*}{ CV (\%) } \\
\hline & 0 & 8,7 & 17,4 & 26,1 & 34,8 & \\
\hline \multicolumn{6}{|l|}{ Saída de nitrogênio, g/dida } & 8,50 \\
\hline Leite & 86,21 & 76,04 & 81,65 & 82,76 & 76,18 & 16,92 \\
\hline Urina & 94,50 & 98,10 & 95,69 & 102,21 & 91,54 & 16,56 \\
\hline Fezes & 124,00 & 125,55 & 130,11 & 135,47 & 114,12 & 29,80 \\
\hline & & Efici & de utiliz & nitrogêni & & \\
\hline Eficiência $\mathrm{N}$ & 0,242 & 0,227 & 0,241 & 0,237 & 0,233 & 14,23 \\
\hline NUL (mg/dL) & 14,40 & 15,59 & 14,33 & 14,93 & 16,97 & 22,97 \\
\hline NUS (mg/dL) & 18,17 & 17,89 & 18,73 & 18,73 & 21,53 & 22,71 \\
\hline
\end{tabular}

Tabela 7 - Consumo de matéria seca, produção de leite, leite corrigido para 3,5\% de gordura (LCG 3,5), eficiência alimentar e variação do peso vivo decorrente das dietas experimentais

\begin{tabular}{|c|c|c|c|c|c|c|c|}
\hline \multirow[t]{2}{*}{ Item } & \multicolumn{5}{|c|}{ Nível de farelo de algodão alta energia no concentrado (\%) } & \multirow[t]{2}{*}{ Média } & \multirow[t]{2}{*}{$\mathrm{CV}(\%)$} \\
\hline & 0 & 8,7 & 17,4 & 26,1 & 34,8 & & \\
\hline Produção de leite (kg/dia) & 14,73 & 13,28 & 14,49 & 14,44 & 13,20 & 14,03 & 18,46 \\
\hline LCG 3,5 (kg/dia) & 15,30 & 13,90 & 15,03 & 15,04 & 14,14 & 14,68 & 22,45 \\
\hline Eficiência alimentar & 1,032 & 1,015 & 1,074 & 1,034 & 1,040 & 1,039 & 21,57 \\
\hline Variação do peso vivo (g/dia) & 1,076 & 0,234 & 0,511 & 0,427 & 0,226 & 0,495 & 76,08 \\
\hline
\end{tabular}


produzindo em média 23,4 kg de leite/dia; Blackwelder et al. (1998), que utilizaram farelo de algodão (16,2 e 9,4\%) em dietas com $17 \%$ de PB e obtiveram produção média diária de 47,5 kg de leite/dia; e Maesoomi et al. (2006), que incluíram 9,0 e 26,3\% de farelo de algodão em dietas contendo $17,2 \%$ de $\mathrm{PB}$ (base na MS), resultando em produção média de 28,0 kg de leite/dia.

$\mathrm{O}$ que diferenciou marcadamente os resultados obtidos neste trabalho em relação aos citados anteriormente foi o menor CMS encontrado. Entretanto, Oliveira (2007), trabalhando com animais do mesmo rebanho e dieta com valor nutritivo equivalente ao deste estudo, observou resultados semelhantes $(\mathrm{CMS}=12,48 \mathrm{~kg} \mathrm{MS} / \mathrm{dia}$ e $\mathrm{PL}=$ $12,98 \mathrm{~kg}$ de leite/dia), o que permite supor que a limitação ao consumo foi de ordem genética, uma vez que, conforme o NRC (2001), o consumo é direcionado pela produção de leite dos animais.

A eficiência alimentar (LCG 3,5/CMS) também não foi influenciada pela inclusão do farelo de algodão de alta energia ( $\mathrm{P}>0,05$, Tabela 7 ), porque também não houve efeito da inclusão sobre o consumo (Tabela 4) e a produção de leite (Tabela 7). Resultado semelhante foi obtido por Maesoomi et al. (2006), que obtiveram eficiência alimentar de 1,05, e Imaizumi (2005), que avaliou o efeito da substituição parcial (50\%) ou total do farelo de soja por farelo de algodão em dietas com teor de PB acima de 16\% (com base na MS), com valores para eficiência alimentar de 1,59 e 1,63, respectivamente para a substituição parcial (50\%) e total do farelo de soja pelo farelo de algodão.

\section{Conclusões}

O farelo de algodão de alta energia tem potencial para substituir o farelo de soja na alimentação de vacas de média produção recebendo rações com 14\% de proteína bruta na matéria seca em até 34,8\% da matéria seca do concentrado; seu uso depende, portanto, das variações de mercado.

\section{Agradecimentos}

À Bunge Alimentos, pelo apoio financeiro e pelos ingredientes utilizados na formulação das dietas.

\section{Referências}

BEQUETTE, B.J.; BACKWELL, F.R.C.; CROMPTON, L.A. Current concepts of amino acid and protein metabolism in the mammary gland of the lactating ruminant. Journal of Dairy Science, v.81, n.9, p.2540-2559, 1998.
BLACKWELDER, J.T.; HOPKINS, B.A; DIAZ, D.E. et al. Milk production and plasma gossypol of cows fed cottonseed and oilseed meals with or without rumen-undegradable protein. Journal of Dairy Science, v.81, n.11, p.2934-2941, 1998.

BRODERICK, G.A.; CLAYTON, M.K. A statistical evaluation of animal and nutritional factors influencing concentrations of milk urea nitrogen. Journal of Dairy Science, v.80, n.11, p.2964-2971, 1997.

BRODERICK, G.A. Effects of varying dietary protein and energy levels on the production of lactating dairy cows. Journal of Dairy Science, v.86, n.4, p.1370-1381, 2003.

BUNGE ALIMENTOS. Farelo de algodão de alta energia. Disponível em:<http://www.bungealimentos.com.br/nutricao/ artigos.asp?id=3048>. Acesso em: 7/7/2007.

CHIZZOTTI, M.L.; VALADARES FILHO, S.C.; VALADARES, R.F.D. et al. Consumo, digestibilidade e excreção de uréia e derivados de purinas em vacas de diferentes níveis de produção de leite. Revista Brasileira de Zootecnia, v.36, n.1, p.138-146, 2007.

COCHRAN, R.C.; ADAMS, D.C.; WALLACE, J.D. et al. Predicting digestibility diets with internal markers: Evaluation of four potential markers. Journal of Animal Science, v.63, n.5, p.1476-1483, 1986.

COLMENERO, J.J.O.; BRODERICK, G.A. Effect of dietary crude protein concentration on milk production and nitrogen utilization in lactating dairy cows. Journal of Dairy Science, v.89, n.5, p.1704-1712, 2006.

CORDEIRO, C.F.A.; PEREIRA, M.L.A.; MENDONÇA, S.S. et al. Consumo e digestibilidade total dos nutrientes e produção e composição do leite de vacas alimentadas com teores crescentes de proteína bruta na dieta contendo cana-de-açúcar e concentrados. Revista Brasileira de Zootecnia, v.36, n.6, p.2118-2126, 2007 (supl.).

DETMANN, E.; QUEIROZ, A.C.; CECON, P.R. et al. Consumo de fibra em detergente neutro por bovinos em confinamento. Revista Brasileira de Zootecnia, v.32, n.6, p.1763-1777, 2003 (supl. 1).

IMAIZUMI, H. Suplementação protéica, uso de subprodutos agroindustriais e processamento de milho em dietas para vacas leiteiras em confinamento. 2005. 196f. Tese (Doutorado em Agronomia) - Escola Superior de Agricultura Luiz de Queiroz, Piracicaba.

IPHARRAGUERRE, I.R.; CLARK, J.H. Varying protein and starch in the diet of dairy cows. II. Effects on performance and nitrogen utilization for milk production. Journal of Dairy Science, v.88, n.7, p.2556-2570, 2005.

JONKER, J.S.; KOHN, R.A.; ERDMAN, R.A. Using milk urea nitrogen to predict nitrogen excretion and utilization efficiency in lactating dairy cows. Journal of Dairy Science, v.81, n.10, p.2681-2691, 1998.

JONKER, J.S.; KOHN, R.A.; HIGH, J. Use of milk urea nitrogen to improve dairy cow diets. Journal of Dairy Science, v.85, n.4, p.939-946, 2002.

LEITE, L.A.; SILVA, B.O; REIS, R.B. et al. Silagens de girassol e de milho em dietas de vacas leiteiras: consumo e digestibilidade aparente. Arquivo Brasileiro de Medicina Veterinária e Zootecnia, v.58, n.6, 2006.

MAESOOMI, S.M.; GHORBANI, G.R.; ALIKHANI, M. et al. Short communication: canola meal as a substitute for cottonseed meal in diet of midlactation Holsteins. Journal of Dairy Science, v.89, n.5, p.1673-1677, 2006.

MERTENS, D.R. Predicting intake and digestibility using mathematical models of ruminal function. Journal of Animal Science, v.64, n.5, p.1548-1558, 1987.

NATIONAL RESEARCH COUNCIL - NRC. Nutrients requirements of dairy cattle. 7.ed. Washington: National Academy Press, 2001. 381p.

OLIVEIRA, A.S.; VALADARES, R.F.D.; VALADARES FILHO, S.C. et al. Consumo e digestibilidade aparente, produção e composição do leite em vacas alimentadas com quatro níveis de 
compostos nitrogenados não-protéicos. Revista Brasileira de Zootecnia, v.30, n.4, p.1358-1366, 2001.

OLIVEIRA, I.S. Avaliação de volumosos na dieta de vacas leiteiras na época seca: consumo, digestibilidade, produção de leite e simulação do CNCPS. 2007. 76f. Dissertação (Mestre em Ciência Animal) - Universidade Federal de Mato Grosso, Cuiabá.

PINA, D.S.; VALADARES FILHO, S.C.; VALADARES, R.F.D. et al. Síntese de proteína microbiana e concentrações de uréia em vacas alimentadas com diferentes fontes de proteína. Revista Brasileira de Zootecnia, v.35, p.1552-1559, 2006a.

PINA, D.S.; VALADARES FILHO, S.C.; VALADARES, R.F.D. et al. Consumo e digestibilidade aparente total dos nutrientes, produção e composição do leite de vacas alimentadas com dietas contendo diferentes fontes de proteína. Revista Brasileira de Zootecnia, v.35, n.4, p.1543-1551, 2006b.

RENNÓ, F.P.; PEREIRA, J.C.; LEITE, C.A.M. et al. Eficiência bioeconômica de vacas de diferentes níveis de produção de leite por lactação e estratégias de alimentação. Revista Brasileira de Zootecnia, v.37, n.4, p.765-772, 2008.

SANTOS, F.A.P.; SANTOS, J.E.P.; THEURER, C.B. et al. Effects of rumen -undegradable protein on dairy cow performance: a 12-year literature review. Journal of Dairy Science, v.81, n.12, p.3182-3213, 1998.

SKLAN, D.; ASHKENAZI, R.; BRAUN, A. et al. Fatty acids, calcium soaps of fatty acids, and cottonseeds fed to high yielding cows. Journal of Dairy Science, v.75, n.9, p.24632472, 1992.

SILVA, D.J.; QUEIROZ, A.C. Análise de alimentos: métodos químicos e biológicos. 3.ed. Viçosa, MG: Universidade Federal de Viçosa, 2002. 235p.

SILVA, R.M.N.; VALADARES, R.F.D.; VALADARES FILHO, S.C. et al. Uréia para vacas em lactação. 1. Consumo, digestibilidade, produção e composição do leite. Revista Brasileira de Zootecnia, v.30, n.5, p.1639-1649, 2001.

SNIFFEN, C.J.; O'CONNOR, J.D.; VAN SOEST, P.J. et al. A net carbohydrate and protein system for evaluating cattle diets; II. Carbohydrate and protein availability. Journal of Animal Science, v.70, n.11, p.3562-3577, 1992.

STATISTICAL ANALYSIS SYSTEM - SAS. The statistical analyze systems for windows: version 8. Cary, 1999-2001. (CD-ROM).

VALADARES FILHO, S.C.; BRODERICK, G.A.; VALADARES, R.F.D. et al. Effect of replacing alfafa silage with high moisture corn on nutrient utilization and milk production. Journal of Dairy Science, v.83, n.1, p.106-114, 2000.

VAN SOEST, P.J.; ROBERTSON, J.B.; LEWIS, B.A. Methods for dietary fiber, neutral detergent fiber, and nonstarch polysaccharides in relation to animal nutrition. Journal of Dairy Science, v.74, n.10, p.3583-3597, 1991. 